Article

\title{
Psychiatric Illness and Medical Decision-Making Capacity: A Retrospective Study in Medical Settings
}

\author{
Dinesh Sangroula ${ }^{1,2, *}$, Pranita Mainali ${ }^{3}$, Katsuhiko Hagi ${ }^{4}\left(\mathbb{D}\right.$ and Sachidanand Peteru ${ }^{1}$ \\ 1 Dartmouth-Hitchcock Medical Center, Lebanon, NH 03756, USA; speteru@jhmc.org \\ 2 Department of Psychiatry, Jamaica Hospital Medical Center, Jamaica, NY 11418, USA \\ 3 Nassau University Medical Center, New York, NY 11554, USA; pranitamainali2@gmail.com \\ 4 Sumitomo Dainippon Pharma Co., Ltd., Medical Affairs, Tokyo 104-8356, Japan; \\ katsuhiko-hagi@ds-pharma.co.jp \\ * Correspondence: Dinesh.Sangroula@hitchcock.org
}

Received: 18 September 2020; Accepted: 30 November 2020; Published: 2 December 2020

\begin{abstract}
Determination of medical decision-making capacity (DMC) is one of the common encounters in Consultation-Liaison Psychiatry (CLP) services. It is a common misbelief that patients with "psych history" lack capacity more often than patients without mental illness. The study aims to examine the relationship between mental illness and DMC in patients presented to acute medical settings. The study is a retrospective chart review, where data were collected from the patients admitted to the medical units and assessed for capacity by a psychiatrist. Clinical and demographic characteristics were compared between two groups (patients having capacity and lacking capacity) using $t$-tests or chi-square tests, as appropriate. The commonest reason for DMC evaluation requests was for the patients who wanted to leave the hospital against medical advice. Overall, 53\% (52/98) of the patients evaluated for DMC were found to lack capacity. Group of patients lacking DMC had a significantly higher percentage of males (58\% vs. $35 \%$ ) but were significantly less employed ( $8 \%$ vs. $10 \%)$. No significant difference was observed in other demographic characteristics and primary psychiatric diagnoses (past and current) among the two groups. However, patients lacking capacity were found to have a significantly more occurrence of current ( $48 \%$ vs. $11 \%)$ and past $(23 \%$ vs. $4 \%)$ history of neurocognitive disorder, and larger trend significance ( $31 \%$ vs. $15 \%$ ) of active psychiatric symptoms. We conclude that patients with neurocognitive disorders and active psychiatric symptoms might have poor DMC but not all patients who have psychiatric diagnoses lack medical DMC. Larger studies especially in outpatient psychiatric settings are suggested to derive more conclusive results.
\end{abstract}

Keywords: capacity determination; psychiatric illness; competency

\section{Introduction}

Determination of capacity to make a medical decision is one of the common reasons for psychiatric consultation among patients presented to the medical emergency room or medical/surgical inpatient units. Medical decision-making capacity (DMC) is the term used to define an ability of a person to make an informed decision for his/her specific medical care at a given time. It is often interchangeably used with competence, which refers to the degree of a person's mental soundness to make a decision about a specific issue or to carry out a specific act. While capacity is usually determined by a physician, competence is a judicial determination made by a court of law [1]. A study conducted in Kings County Hospital, New York showed that about 25\% of psychiatric consultation in Consult-Liaison Psychiatry (CLP) was for a capacity evaluation [2]. The common encounters where a medical team requests that a psychiatrist determine capacity are for acutely ill patients who are unable to consent or refuse to consent to treatment (testing or procedures or medications) and for patients who wish to leave 
the hospital against medical advice (AMA). While a study conducted in the UK with patients admitted to a psychiatry ward indicated common reasons for assessing capacity being (a) to consent to psychiatry admission and treatment, (b) to consent to divorce and marriage, (c) to make a will, and (d) to refuse to share medical records and life-saving treatment. The majority of the patients were found to lack capacity (63.6\%) where organic syndrome, schizophrenia spectrum disorder, bipolar disorder, and depressive disorders were diagnoses, associated in the order of prevalence. These groups of patients were symptomatic patients requiring inpatient psychiatric treatment [3].

It is important to understand that medical DMC applies to a specific situation or purpose at a specific time. A patient could be capable of making a medical decision in one area but might be incapable of others [4]. For instance, a patient who is found to have capacity to refuse a surgical procedure may not have capacity to sign for discharge AMA. Similarly, patients fond to lack capacity today might be judged to have the capacity in three days. Moreover, medical DMC might not be permanent and a patient can lose capacity due to an acute medical condition which can return back after treatment $[5,6]$.

There are four components that are assessed to determine if a person has/lacks capacity: (i) Does the patient understand the relevant information and details of the fact? (ii) Does the patient appreciate the situation and its consequences? (iii) Does the patient have the ability to communicate a choice? (iv) Does the patient rationalize the reason for treatment options [7]? CLP services commonly reference Applebaum's above principle for the clinical interview in clinical practice but in a research setting, different tools have been studied. MacArthur Competence Assessment Tool (Mac Arthur-CAT) is the most commonly used among others. It is to be noted that during the capacity assessment, if an individual lacks any one of the four components as described above, they are considered as incapable of medical decision-making.

Ganzini et al. indicated that one of the common myths about capacity determination is that all patients who have psychiatric disorders and are involuntarily committed are presumed to not have DMC. This might not always be true, especially for patients with chronic but stable psychiatric symptoms and patients admitted to a medical or surgical inpatient unit for acute physical conditions. Additionally, it is falsely believed that only mental health experts can evaluate DMC [5]. Because of the above-mentioned misbeliefs, it has been observed that, in clinical practice, there is a higher tendency for the medical team to call psychiatric consultation for capacity determination of patients with a history of psychiatric disorder compared to patients without psychiatric disorders. That might be feasible and appropriate for the hospitals with sufficient resources of CLP services but it might be challenging for the hospitals in rural settings or having limited/no consult liaison psychiatrists.

The primary objective of this study is to compare the demographic and clinical characteristics between patients with capacity vs. without capacity and to explore the possible association of prior psychiatric diagnoses (neurocognitive disorder, adjustment disorder, and substance use disorder were examined separately and were excluded from primary psychiatric diagnoses) with lack of DMC in patients admitted with acute medical or surgical problems.

\section{Method}

A retrospective chart review study was conducted including adult patients ( $>18$ years of age) who were admitted to the medical emergency room or inpatient units between 1 February 2017 and 31 January 2018 and assessed by the CLP team for DMC. The capacity evaluation was conducted in-person by either (a) the residents who were rotating in the CLP services during the weekdays supervised by 2 or 3 different attending consult-liaison psychiatrists, or (b) the residents on-call during the weekends and weeknights supervised by the on-call attending psychiatrist (variable). None of the standard capacity evaluation tools were used and evaluation was based on the clinical judgement of the evaluator. Exclusion criteria included the diagnosis of mental retardation, follow-up consults, and notes that were not signed by the attending psychiatrist. We followed the principles of the Declaration of Helsinki and the study was reviewed and approved by the Institutional Review Board (IRB) at Jamaica Hospital 
Medical Center, NY. Since it was only a chart review from the hospital's electronic medical record without any intervention, informed consent was not taken from the patient.

Data collection included demographic variables, present or past substance use, presence or absence of active psychiatric symptoms, psychiatric diagnoses (overall and specific), reasons for capacity evaluation, and results of capacity determination (yes/no) (Table 1). Subjects were divided into two groups-patients lacking DMC (Group A) and having DMC capacity (Group B) and a retrospective case-control study was conducted. The association between psychiatric illness and DMC was assessed by way of multiple chi-square tests, using SPSS. We performed our analyses without adjustment for multiple comparisons as this research was an exploratory study with multiple outcomes.

Table 1. Demographic characteristics comparison between two groups.

\begin{tabular}{|c|c|c|c|c|c|}
\hline Variables & Subgroups & $\begin{array}{l}\text { No Capacity } \\
\text { (A) }(n=52)\end{array}$ & $\begin{array}{l}\text { With Capacity } \\
\text { (B) }(n=46)\end{array}$ & Test/Statistics & $p$-Value \\
\hline \multirow[t]{5}{*}{ Mean Age (SD) } & & $59.8(17.0)$ & $54.8(16.7)$ & $\mathrm{T}=1.45$ & 0.15 \\
\hline & $18-30$ years & $3(6 \%)$ & $5(11 \%)$ & $X^{2}=0.85$ & 0.36 \\
\hline & $31-40$ years & $7(14 \%)$ & $4(9 \%)$ & $X^{2}=0.56$ & 0.46 \\
\hline & $41-65$ years & $22(42 \%)$ & $24(52 \%)$ & $X^{2}=0.95$ & 0.33 \\
\hline & 65 years & $20(38 \%)$ & $13(28 \%)$ & $X^{2}=1.14$ & 0.29 \\
\hline Male gender (\%) & & $30(58 \%)$ & $16(35 \%)$ & $X^{2}=5.14$ & 0.02 \\
\hline \multirow[t]{7}{*}{ Ethnicity } & & & & $X^{2}=4.07$ & 0.54 \\
\hline & White & $12(23 \%)$ & $13(28 \%)$ & $X^{2}=0.35$ & 0.56 \\
\hline & $\mathrm{AA}$ & $24(46 \%)$ & $13(28 \%)$ & $x^{2}=3.33$ & 0.07 \\
\hline & Hispanic & $7(13 \%)$ & $7(15 \%)$ & $X^{2}=0.06$ & 0.80 \\
\hline & Asian & $3(6 \%)$ & $6(13 \%)$ & $X^{2}=1.55$ & 0.21 \\
\hline & Guyanese & $2(4 \%)$ & $2(4 \%)$ & $X^{2}=0.02$ & 0.90 \\
\hline & NR/unknown & $4(8 \%)$ & $5(11 \%)$ & $X^{2}=0.30$ & 0.59 \\
\hline \multirow[t]{6}{*}{ Marital Status } & & & & $X^{2}=3.76$ & 0.44 \\
\hline & Single & $23(44 \%)$ & $27(59 \%)$ & $X^{2}=2.04$ & 0.15 \\
\hline & Married & $10(19 \%)$ & $5(11 \%)$ & $X^{2}=1.32$ & 0.25 \\
\hline & Divorced & $9(17 \%)$ & $4(8 \%)$ & $X^{2}=1.57$ & 0.21 \\
\hline & Widow (er) & $4(8 \%)$ & $5(11 \%)$ & $X^{2}=0.30$ & 0.59 \\
\hline & NR/unknown & $6(12 \%)$ & $5(11 \%)$ & $X^{2}=0.01$ & 0.92 \\
\hline \multirow[t]{5}{*}{ Employment status } & & & & $X^{2}=4.33$ & 0.23 \\
\hline & $0=$ Unemployed & $41(79 \%)$ & $32(70 \%)$ & $X^{2}=1.11$ & 0.29 \\
\hline & 1 = Employed & $4(8 \%)$ & $10(22 \%)$ & $X^{2}=3.93$ & 0.05 \\
\hline & $2=$ Retired & $1(2 \%)$ & $1(2 \%)$ & $X^{2}=0.01$ & 0.93 \\
\hline & $3=\mathrm{NR} /$ unknown & $6(12 \%)$ & $3(7 \%)$ & $X^{2}=0.74$ & 0.39 \\
\hline \multirow[t]{4}{*}{ Living situation } & & & & $X^{2}=2.02$ & 0.37 \\
\hline & $0=$ Homeless & $6(12 \%)$ & $7(15 \%)$ & $X^{2}=0.29$ & 0.59 \\
\hline & $1=$ Domiciled & $44(85 \%)$ & $39(85 \%)$ & $X^{2}=0.00$ & 0.98 \\
\hline & $2=\mathrm{NR} /$ unknown & $2(4 \%)$ & 0 & $X^{2}=1.81$ & 0.18 \\
\hline \multirow[t]{2}{*}{ Social Situation } & & & & $X^{2}=2.45$ & 0.29 \\
\hline & $0=$ Poor & $24(46 \%)$ & $28(61 \%)$ & $X^{2}=2.12$ & 0.15 \\
\hline
\end{tabular}


Table 1. Cont.

\begin{tabular}{|c|c|c|c|c|c|}
\hline Variables & Subgroups & $\begin{array}{l}\text { No Capacity } \\
\text { (A) }(n=52)\end{array}$ & $\begin{array}{l}\text { With Capacity } \\
\text { (B) }(n=46)\end{array}$ & Test/Statistics & $p$-Value \\
\hline & $1=$ Good & $25(48 \%)$ & $15(33 \%)$ & $X^{2}=2.42$ & 0.12 \\
\hline & $2=\mathrm{NR} /$ unknown & $3(6 \%)$ & $3(7 \%)$ & $X^{2}=0.02$ & 0.88 \\
\hline \multirow[t]{4}{*}{ Brought in by } & & & & $X^{2}=2.30$ & 0.32 \\
\hline & Self & $3(6 \%)$ & $5(11 \%)$ & $X^{2}=0.85$ & 0.36 \\
\hline & EMS/Ambulance & $48(92 \%)$ & $38(83 \%)$ & $X^{2}=2.14$ & 0.14 \\
\hline & NR/Unknown & $1(2 \%)$ & $3(7 \%)$ & $X^{2}=1.32$ & 0.25 \\
\hline \multirow[t]{4}{*}{ Education } & & & & $X^{2}=1.40$ & 0.50 \\
\hline & $\leq \mathrm{HS}$ & $17(33 \%)$ & $12(26 \%)$ & $X^{2}=0.51$ & 0.47 \\
\hline & $>\mathrm{HS}$ & $6(12 \%)$ & $9(20 \%)$ & $X^{2}=1.21$ & 0.27 \\
\hline & NR/unknown & $29(56 \%)$ & $25(54 \%)$ & $X^{2}=0.02$ & 0.89 \\
\hline \multirow[t]{6}{*}{ Settings } & & & & $x^{2}=3.74$ & 0.44 \\
\hline & Regular Floor & $37(71 \%)$ & $32(70 \%)$ & $X^{2}=0.03$ & 0.86 \\
\hline & Medical ER & $13(25 \%)$ & $9(20 \%)$ & $X^{2}=0.41$ & 0.52 \\
\hline & ICU & $2(4 \%)$ & $2(4 \%)$ & $X^{2}=0.02$ & 0.90 \\
\hline & Others & 0 & $2(4 \%)$ & $X^{2}=2.31$ & 0.13 \\
\hline & NR/Unknown & 0 & $1(2 \%)$ & $X^{2}=1.14$ & 0.29 \\
\hline
\end{tabular}

Note: AA = African American; EMS = Emergency Medical Services; ER = Emergency Room; HS = High School; $\mathrm{ICU}=$ Intensive Care Unit; $n=$ number of subjects; $\mathrm{NR}=$ Not reported; $\mathrm{SD}=$ Standard Deviation.

\section{Result}

A total of 726 consult request charts were screened, out of which 105 consult requests met criteria for the detail chart review in EPIC electronic medical record. In total, seven additional subjects were excluded for either not meeting inclusion criteria or meeting exclusion criteria, leaving 98 total subjects eligible for the study (Flow diagram). In total, 52 out of 98 subjects (53\%) were found to lack DMC (named Group A) while 46 out of 98 subjects (47\%) were determined to have DMC (named Group B). The common reasons to consult psychiatrist for capacity determinations were (i) to sign AMA $(n=37$, $37.7 \%)$, (ii) refusal of medication/tests/procedures $(n=32,32.6 \%)$, (iii) non-specific reasons $(n=3,3 \%)$, and (iv) unconscious or intubated ( $n=1,1 \%$ ) (flow diagram here).

Demographic characteristics comparison of subjects between two groups:

Group of patients lacking DMC had a significantly higher percentage of males than the group having DMC (A58\% vs. B35\%, $\left.\mathrm{X}^{2}=5.14, p=0.02\right)$. Additionally, the number of employed patients were significantly lower in Group A than in Group B (A8\% vs. B22\%, $\left.\mathrm{X}^{2}=3.93, p=0.05\right)$ but no significant difference was observed between groups in terms of overall employment status $\left(\mathrm{X}^{2}=4.33, p=0.23\right)$. Mean age of the patients with capacity was 54.8 years (SD of 16.7), while 59.8 years (SD of 17.0) for patients without capacity. Interestingly, $46 \%$ of patients lacking capacity were African American while $28 \%$ of Group B were African Americans (AAs) $\left(\mathrm{X}^{2}=3.33, p=0.07\right.$ ). No significant difference was evidenced among two compared groups in terms of marital status (married or single or divorced or so on), living situation (homeless or domiciled or unknown), social situation, mode of transportation to the hospital, educational status, and location of the patient in the hospital (regular floor or medical ED or Intensive Care Unit (ICU) and so on) (Table 1).

Clinical characteristics comparison between two groups:

In terms of psychiatric history, a large proportion of patients who had consults called had a past history significant for psychiatric issues $(n=39,39.8 \%)$, drug and alcohol abuse $(n=52,53 \%)$, dual diagnosis $(n=25,25.5 \%)$, and around $20 \%$ of all patients had a past psychiatric admission. 
However, there was no significant difference between two groups (Group A vs. Group B, respectively) in terms of having overall past psychiatric diagnoses (A35\% vs. B46\%, $p=0.27$ ), and specific past psychiatric diagnoses including depressive disorders (A10\% vs. B15\%, $p=0.40$ ), bipolar and related disorders (A6\% vs. B13\%, $p=0.21$ ), schizophrenia spectrum disorders (A17\% vs. B24\%, $p=0.42$ ), anxiety disorders (A12\% vs. B8\%, $p=0.64$ ), and so on. However, in the group lacking capacity, significantly larger numbers of subjects had a past history of neurocognitive disorders (A23\% vs. B4\%, $\mathrm{X}^{2}=6.99$, $p=0.008$ ) than Group B (Table 2). Similarly, there was no significant difference between two groups in terms of having overall current psychiatric diagnoses (A50\% vs. B56\%, $p=0.52$ ), dual diagnoses (A35\% vs. B24\%, $p=0.25$ ), substance use disorders (A37\% vs. B43\%, $p=0.48$ ), and specific current psychiatric diagnoses including depressive disorders (A13\% vs. B22\%, $p=0.28$ ), bipolar and related disorders (A4\% vs. B8\%, $p=0.32$ ), schizophrenia spectrum disorders (A17\% vs. B24\%, $p=0.42$ ), anxiety disorders (A10\% vs. B15\%, $p=0.40$ ), and so on. As expected, Group A had remarkably larger numbers of subjects with current neurocognitive disorders (A48\% vs. B11\%, $\mathrm{X}^{2}=15.91, p<0.001$ ) than Group B (Table 2). Notably, there was also a trend significance for the presence of active psychiatric symptoms during the time of evaluation among the group lacking capacity (A31\% vs. B15\%, $\mathrm{X}^{2}=3.29$, $p=0.07)$. Interestingly, patients with capacity were found to have trend significance for past history (but not current) of alcohol use than without capacity (A33\% vs. B50\%, $\mathrm{X}^{2}=3.03, p=0.08$ ) (Table 2).

Table 2. Comparison of results between two groups.

\begin{tabular}{|c|c|c|c|c|c|}
\hline Variables & Subgroups & $\begin{array}{c}\text { No Capacity } \\
\text { (A) } \\
(n=52)\end{array}$ & $\begin{array}{c}\text { With Capacity } \\
\text { (B) } \\
(n=46)\end{array}$ & Statistics & $p$-Value \\
\hline \multicolumn{6}{|c|}{ Past psychiatric history } \\
\hline \multirow{8}{*}{$\begin{array}{l}\text { Psychiatric } \\
\text { diagnosis }\end{array}$} & Overall diagnosis & $18(35 \%)$ & $21(46 \%)$ & $X^{2}=1.24$ & 0.27 \\
\hline & Dual diagnosis & $11(21 \%)$ & $14(30 \%)$ & $X^{2}=1.11$ & 0.29 \\
\hline & Depressive ds & $5(10 \%)$ & $7(15 \%)$ & $X^{2}=0.71$ & 0.40 \\
\hline & Bipolar and related ds & $3(6 \%)$ & $6(13 \%)$ & $X^{2}=1.55$ & 0.21 \\
\hline & $\begin{array}{l}\text { Schizophrenia } \\
\text { spectrum ds }\end{array}$ & $9(17 \%)$ & $11(24 \%)$ & $X^{2}=0.66$ & 0.42 \\
\hline & Anxiety ds & $6(12 \%)$ & $4(8 \%)$ & $X^{2}=0.22$ & 0.64 \\
\hline & Personality ds & $3(6 \%)$ & 0 & $X^{2}=2.74$ & 0.10 \\
\hline & PTSD & $2(4 \%)$ & $2(4 \%)$ & $X^{2}=0.02$ & 0.90 \\
\hline Past suicidality & & $3(6 \%)$ & $6(13 \%)$ & $X^{2}=1.55$ & 0.21 \\
\hline Hospitalization & & $8(15 \%)$ & $12(26 \%)$ & $X^{2}=1.72$ & 0.19 \\
\hline \multirow{3}{*}{ Substance use } & Overall & $25(48 \%)$ & $27(59 \%)$ & $X^{2}=1.11$ & 0.29 \\
\hline & Alcohol use & $17(33 \%)$ & $23(50 \%)$ & $X^{2}=3.03$ & 0.08 \\
\hline & Illicit substances & $14(27 \%)$ & $15(33 \%)$ & $X^{2}=0.38$ & 0.54 \\
\hline Neurocognitive ds & $\begin{array}{l}\text { Dementia and } \\
\text { Delirium }\end{array}$ & $12(23 \%)$ & $2(4 \%)$ & $X^{2}=6.99$ & 0.008 \\
\hline \multicolumn{6}{|c|}{ Current psychiatric history } \\
\hline \multirow{5}{*}{$\begin{array}{c}\text { Current psychiatric } \\
\text { diagnosis }\end{array}$} & $\begin{array}{c}\text { Overall psychiatric } \\
\text { diagnoses }\end{array}$ & $26(50 \%)$ & $26(56 \%)$ & $X^{2}=0.42$ & 0.52 \\
\hline & Dual diagnosis & $18(35 \%)$ & $11(24 \%)$ & $X^{2}=1.34$ & 0.25 \\
\hline & Depressive ds & $7(13 \%)$ & $10(22 \%)$ & $X^{2}=1.17$ & 0.28 \\
\hline & Bipolar and related ds & $2(4 \%)$ & $4(8 \%)$ & $X^{2}=1.00$ & 0.32 \\
\hline & $\begin{array}{l}\text { Schizophrenia } \\
\text { spectrum ds }\end{array}$ & $9(17 \%)$ & $11(24 \%)$ & $X^{2}=0.66$ & 0.42 \\
\hline
\end{tabular}


Table 2. Cont.

\begin{tabular}{|c|c|c|c|c|c|}
\hline Variables & Subgroups & $\begin{array}{c}\text { No Capacity } \\
\text { (A) } \\
(n=52)\end{array}$ & $\begin{array}{c}\text { With Capacity } \\
\text { (B) } \\
(n=46)\end{array}$ & Statistics & $p$-Value \\
\hline & Anxiety ds & $5(10 \%)$ & $7(15 \%)$ & $X^{2}=0.71$ & 0.40 \\
\hline & Personality ds & $3(6 \%)$ & 0 & $X^{2}=2.74$ & 0.10 \\
\hline & PTSD & $1(2 \%)$ & $2(4 \%)$ & $X^{2}=0.48$ & 0.49 \\
\hline Active symptoms & & $16(31 \%)$ & $7(15 \%)$ & $X^{2}=3.29$ & 0.07 \\
\hline \multirow[t]{3}{*}{ Medications } & Not recommended & $35(67 \%)$ & $31(67 \%)$ & $X^{2}=0.00$ & 0.99 \\
\hline & $\begin{array}{l}\text { Recommended, } \\
\text { compliant }\end{array}$ & $15(29 \%)$ & $12(26 \%)$ & $X^{2}=0.09$ & 0.76 \\
\hline & $\begin{array}{l}\text { Recommended, } \\
\text { non-compliant }\end{array}$ & $2(4 \%)$ & $3(7 \%)$ & $X^{2}=0.36$ & 0.55 \\
\hline \multirow[t]{3}{*}{ Substance use } & Overall & $19(37 \%)$ & $20(43 \%)$ & $X^{2}=0.49$ & 0.48 \\
\hline & Alcohol use disorder & $15(29 \%)$ & $14(33 \%)$ & $X^{2}=0.03$ & 0.86 \\
\hline & Illicit substance use & $11(21 \%)$ & $13(30 \%)$ & $X^{2}=0.67$ & 0.41 \\
\hline Adjustment ds & & $8(15 \%)$ & $3(7 \%)$ & $X^{2}=1.92$ & 0.17 \\
\hline Neurocognitive ds & $\begin{array}{l}\text { Dementia and } \\
\text { Delirium }\end{array}$ & $25(48 \%)$ & $5(11 \%)$ & $X^{2}=15.91$ & $<0.001$ \\
\hline \multicolumn{6}{|c|}{ Reason for need of capacity determination } \\
\hline \multirow[t]{5}{*}{ Reason for capacity } & $\begin{array}{c}\text { Refusing } \\
\text { test/meds/procedures }\end{array}$ & $18(35 \%)$ & $14(39 \%)$ & $X^{2}=0.19$ & 0.66 \\
\hline & Signing AMA & $18(35 \%)$ & $19(41 \%)$ & $X^{2}=0.46$ & 0.50 \\
\hline & Unconscious/intubated & $1(2 \%)$ & 0 & $X^{2}=0.89$ & 0.34 \\
\hline & $\begin{array}{l}\text { Discharge/disposition } \\
\text { planning }\end{array}$ & $13(25 \%)$ & $12(26 \%)$ & $X^{2}=0.02$ & 0.90 \\
\hline & Non-specific & $2(4 \%)$ & $1(2 \%)$ & $X^{2}=0.23$ & 0.63 \\
\hline
\end{tabular}

Note: AMA = Against medical advice; $\mathrm{ds}=$ disorder; $n=$ number of subjects; PTSD: post-traumatic stress disorder.

\section{Discussion}

The concept of this paper was initiated by the authors while working as part of the CLP services of a community hospital of New York City after hearing multiple times from the medical team, "this patient has a psych history, let's call for capacity" when a patient with psychiatric history in the chart wanted to sign AMA or refused treatment. The majority of patients in our study were found to have some form of psychiatric illness which supported the hypothesis of the study about increased tendency to call the consult if psychiatric history is mentioned in the patient's medical record. This misconception of "patient with psychiatric disorder lacks capacity" has also been mentioned as one of the 10 myths of capacity determination [5]. The result from this study opposes the misconception that individuals with mental illness lack DMC except for the cases of neurocognitive disorders (dementia and delirium) and for patients with active psychiatric symptoms. There is a wide range of findings to estimate the prevalence and predictors of the poor DMC in different settings. A prior study conducted among psychiatric inpatients to examine the prevalence and predictors of DMC has found that $43.8 \%$ of psychiatric inpatients lack capacity [8]. This is comparable to a rate of about $40 \%$ of incapacity found among acutely ill inpatients in medical and/or surgical settings [9]. A systematic review of 58 studies comparing DMC in two different settings (35 in psychiatry settings and 23 in medical settings) illustrated a $45 \%$ vs. $34 \%$ prevalence of lack of DMC, respectively $(p=0.092)$ [10]. In psychiatry inpatient settings, acute manic episodes, acute psychosis, and severe depression are 
commonly associated with impairment of DMC, whereas in medical settings organic brain syndrome, delirium, and neurological conditions are linked with poor DMC [8-10]. Evidence showed that even a mild to moderate cognitive impairment in the Chinese population impacted the DMC and repeated presentation did not necessarily improve the capacity in demented patients [11].

Our study demonstrated significant numbers of the capacity determination consult requests (98/726, $13.5 \%$ ) in a community hospital of New York. Another study conducted in Kings County Hospital, New York evidenced an even higher percentage of psychiatry consults being capacity determination (25\%). The same study has postulated that a physician's anxiety of litigation or medico-legal consequences, lack of clear understanding of physicians' duty, and misunderstanding of patients' rights being the possible factors for the increasing number of capacity determination consults. The majority of patients (75\%) in the study evaluated for DMC were found to have the capacity [2]. Another study conducted in Switzerland among patients admitted to the acute medical ward indicated that $73.3 \%$ of patients requesting capacity were found to have the capacity [12]. A similar trend was demonstrated in our study - around half of the patients evaluated for DMC were found to have the capacity.

A systematic review encompassing 37 studies on the capacity determination (32 in voluntary or involuntary psychiatric inpatient units and 5 in medical units) demonstrated that the presence of neurological and cognitive disorders was primarily associated with incapacity in medical inpatient units $[2,13]$ which was replicated in this study. A retrospective study conducted in New York, among 330 medical inpatients concluded that, among the primary psychiatry diagnoses, substance use and psychotic disorders were associated with incapacity (37.2\% and $25 \%$, respectively), while mood disorder was not [14]. This finding was opposed by the result of this study which demonstrated insignificant relations between psychiatric diagnosis and the DMC except for having active psychiatric symptoms and cognitive dysfunction.

Capacity determination in a hospital setting is ideally performed by a psychiatrist but the common belief that it should always be carried out by a psychiatrist is not true [5]. A study conducted in Switzerland among the French speaking population to compare the capacity assessment for patients admitted to the acute medical ward by Silberfeld questionnaires vs. medical team indicated that the medical team's shared decision (residents, chief resident, and nurses) was in best agreement with the psychiatrist's assessment [12]. This signifies that in the absence of a psychiatrist or hospital with limited resources of CLP services, capacity assessments could be effectively conducted by other specialties as well with proper education and training. It might be useful if capacity assessments could be incorporated in the curriculum of the residency training in other specialties as well.

There are several studies which assessed the capacity of patients with mental illness, but all of them were based on inpatient psychiatric settings where the patient usually presents with acute psychiatric symptoms. A cross-sectional study conducted in Kings College London in a psychiatric inpatient facility to assess the capacity among 338 admitted patients using Mac Arthur-CAT and clinical interview indicated that $60 \%$ of the patients lacked capacity. In this study, the majority of the subjects presented with schizophrenia (25\%), psychotic episodes (22\%), bipolar mania (10\%), and schizoaffective disorders (6\%) - the acute phase of all of these is associated with poor cognitive functioning. Additionally, poor DMC was the highest in acute mania while lowest in personality disorders [15]. A systematic review assessing the association of capacity and depression indicated that acute and severe depressive symptoms can affect cognitive abilities, particularly the abilities of appreciation, which might impair the DMC [16]. Similarly, Owen and colleagues postulated that severe depression and mania might interfere with the anticipation of future outcomes affecting the overall decision-making capacity [17]. A recent study conducted in Greece comparing DMC among patients on the medical floor $(n=78)$ with patients diagnosed with schizophrenia in an inpatient psychiatry unit $(n=21)$ using Mac Arthur-CAT-Treatment $(\mathrm{T})$ demonstrated that the patients with schizophrenia had poor DMC. Additionally, positive and negative symptoms were correlated with poor performance. The study concluded that a lack of decision-making capacity is not a rule for schizophrenia and patients on the medical floor do not necessarily have DMC [18]. A recent multi-center 
study conducted in involuntarily admitted patient on the schizophrenia spectrum and with bipolar disorder evidenced poorer DMC among schizophrenia than in bipolar disorders ( $91 \%$ vs. $78 \%, p<0.001$, respectively). The study also highlighted that positive symptoms are associated with poorer capacity to appreciate and reason, while negative symptoms are associated with a poor understanding of treatment recommendations [19].

Capacity determination is also applied in research settings, mostly to determine if the selected subjects are capable of signing the consent to participate in research studies. Morán-Sánchez and colleagues conducted a study to examine the capacity to participate in research among 139 patients with psychiatric diagnoses using MacArthur-CAT-Consent Research (CR). They found that patients with psychotic disorders scored the worst and those with anxiety disorders scored the best in terms of cognitive impairment and global functioning associated with Mac Arthur-CAT scores. Moreover, 30.6\% lacked the capacity to consent to participate in research. They concluded that no absolute conclusion should be drawn about the DMC in an individual depending on diagnosis, but capacity is more correlated with low reasoning scores or low understanding scores [20]. This finding was replicated by another study comparing DMC for research participation among patients with diabetes mellitus, Alzheimer's disease, and schizophrenia. It was found that the patient with diabetes demonstrated the best DMC and the patient with Alzheimer's disease evidenced the worst DMC concluding that cognitive functioning as opposed to diagnosis is the better predictor of the DMC [21].

A cross-sectional study was conducted in London, UK assessing the presence of psychiatric disorders among 159 medically admitted patients evaluated for capacity. It demonstrated no statistically significant difference in the rates of psychiatric diagnoses in patients with capacity vs. those without capacity ( $9 \%$ vs. $12 \%$, respectively, $p=0.4$ ) (which held true in this study), whereas increasing age and cognitive impairment due to neurological disorders were commonly associated with patients lacking DMC [22].

The diagnosis of neurocognitive disorder is not included under the psychiatric diagnoses in this research (though they are the Diagnostic and Statistical Manual-V diagnoses) because they are considered as a neurological disorder than "a psych patient" unless there is associated behavioral disturbances and the aim of the study was to examine the relationship of the primary psychiatric diagnoses (not including neurocognitive disorders) with DMC. The result of our study is also supported by the fact that patients with psychiatric disorders, well treated or well stabilized, are able to function very well in the community and can regain capacity with treatment. A recent study conducted in Ireland to examine the DMC in 55 psychotic patients before and after treatment and stabilization illustrated that the impairment in DMC significantly improved after 12 weeks of treatment (effect size $=0.5-0.6$ ) [23]. In contrast, patients who have active psychiatric symptoms might not be able to fend in the community. They might have poor judgment and/or impaired insight and be hospitalized in the psychiatric facility in which case they might not have capacity to understand, appreciate, and rationalize the choices made; evidenced in both previous studies and our study with trending significance ( $31 \%$ vs. $15 \%, p=0.07)$.

\section{Limitations}

The study was a retrospective chart review with a number of limitations. Not all necessary information was available in the chart and those were collected as "not reported" could have contributed to the biasness of the results. Measurement bias could not be undermined because a standard capacity determination tool was not used and evaluators could have different opinions on each capacity determination consultation. Moreover, the study subjects were from a community hospital in the metropolitan area of Queens, NY which might be different from the university hospital or rural setting or other countries. A small sample size was one of the major limitations of our study and hence definite conclusions about the insignificant relationship between psychiatric illness and DMC cannot be drawn until replicated in a study with a larger sample size. The study could not determine the causation like other retrospective studies but could only provide an inferior level of evidence about the possible association. 


\section{Conclusions}

Based on our findings and literature review, we conclude that patients with neurocognitive disorders and active psychiatric symptoms might have poorer DMC but not all patients who have psychiatric diagnoses are incapable of medical decision-making. We suggest that, in medical settings, consulting psychiatry for capacity determination should be primarily based on the assessment of cognitive function than specific diagnoses. It should not be a routine practice for all patients who have a history of psychiatric disorders, especially if the psychiatric symptoms are stable and resources for CLP services is limited. The implementation of these findings might not only reduce the excessive use of resources of CLP services but also helps preserve patients' autonomy. Larger studies, including subjects from outpatient psychiatric clinics, might be useful to further examine this concept and to derive more conclusive results.

Author Contributions: D.S., as the first and the corresponding author, conceptualized the idea of study, submitted proposal to IRB, and collected data. D.S. and P.M. drafted the manuscript. P.M. also performed literature search, and table/diagram designation. S.P. supervised D.S., provided feedback as needed, involved in IRB submission/ approval, and edited the manuscript draft. K.H. contributed for the statistical analysis, finalizing the results, and assisted in manuscript revision. All authors contributed to, revised, and approved the final manuscript. All authors have read and agreed to the published version of the manuscript.

Funding: This research received no external funding.

Conflicts of Interest: The authors declare no conflict of interest.

\section{References}

1. Sorrentino, R. Performing Capacity Evaluations: What's Expected from Your Consult: Core Components of a Capacity Evaluation Are Understanding, Free Choice, and Reliability. Curr. Psychiatry 2014, 13, 41. Available online: https://www.questia.com/library/journal/1G1-358059460/performing-capacity-evaluationswhat-s-expected-from (accessed on 29 July 2020).

2. Jourdan, J.B.; Glickman, L. Reasons for requests for evaluation of competency in a municipal general hospital. Psychosomatics 1991, 32, 413-416. [CrossRef]

3. Brown, P.F.; Tulloch, A.D.; Mackenzie, C.; Owen, G.S.; Szmukler, G.; Hotopf, M. Assessments of mental capacity in psychiatric inpatients: A retrospective cohort study. BMC Psychiatry 2013, 13, 115. [CrossRef] [PubMed]

4. Maxmin, K.; Cooper, C.; Potter, L.; Livingston, G. Mental capacity to consent to treatment and admission decisions in older adult psychiatric inpatients. Int. J. Geriatr. Psychiatry 2009, 24, 1367-1375. [CrossRef] [PubMed]

5. Ganzini, L.; Volicer, L.; Nelson, W.A.; Fox, E.; Derse, A.R. Ten myths about decision-making capacity. J. Am. Med. Dir. Assoc. 2005, 6, S100-S104. [CrossRef]

6. Searight, H.R.; Montooth, A. Changes in decision making capacity during illness: A review and case report with implications. Arch. Psychiatry Psychother. 2008, 10, 47-55. Available online: http://dartmouth.idm.oclc.org/login?url=http://search.ebscohost.com/login.aspx?direct=true\&AuthType=i p, url,uid\&db=psyh\&AN=2010-15907-006\&site=ehost-live\&scope=site (accessed on 2 August 2020).

7. Appelbaum, P.S. Assessment of Patients' Competence to Consent to Treatment. N. Engl. J. Med. 2007, 257, 1834-1840. [CrossRef]

8. Cairns, R.; Maddock, C.; Buchanan, A.; David, A.S.; Hayward, P.; Richardson, G.; Szmukler, G.; Hotopf, M. Prevalence and predictors of mental incapacity in psychiatric in-patients. Br. J. Psychiatry 2005, 187, 379-385. Available online: http://bjp.rcpsych.org/content/187/4/379.short (accessed on 29 July 2017). [CrossRef]

9. Katz, M.; Abbey, S.; Rydall, A.; Lowy, F. Psychiatric Consultation for Competency to Refuse Medical Treatment. Psychosomatics 1995, 36, 33-41. [CrossRef]

10. Lepping, P.; Stanly, T.; Turner, J. Systematic review on the prevalence of lack of capacity in medical and psychiatric settings. Clin. Med. Lond. Engl. 2015, 15, 337-343. [CrossRef]

11. Lui, V.W.; Lam, L.C.; Luk, D.N.; Wong, L.H.; Tam, C.W.; Chiu, H.F.; Appelbaum, P.S. Capacity to make treatment decisions in Chinese older persons with very mild dementia and mild Alzheimer disease. Am. J. Geriatr. Psychiatry 2009, 17, 428-436. [CrossRef] [PubMed] 
12. Fassassi, S.; Bianchi, Y.; Stiefel, F.; Waeber, G. Assessment of the capacity to consent to treatment in patients admitted to acute medical wards. BMC Med. Ethics 2009, 10, 15. [CrossRef]

13. Okai, D.; Owen, G.; McGuire, H.; Singh, S.; Churchill, R.; Hotopf, M. Mental capacity in psychiatric patients. Br. J. Psychiatry 2007, 191, 291-297. Available online: http://bjp.rcpsych.org/content/bjprcpsych/191/4/291.full. pdf (accessed on 29 July 2017). [CrossRef]

14. Boettger, S.; Bergman, M.; Jenewein, J.; Boettger, S. Assessment of decisional capacity: Prevalence of medical illness and psychiatric comorbidities. Palliat. Support. Care 2015, 13, 1275-1281. [CrossRef]

15. Owen, G.S.; Richardson, G.; David, A.S.; Szmukler, G.; Hayward, P.; Hotopf, M. Mental capacity to make decisions on treatment in people admitted to psychiatric hospitals: Cross sectional study. BMJ 2008, 337, a448. [CrossRef]

16. Hindmarch, T.; Hotopf, M.; Owen, G.S. Depression and decision-making capacity for treatment or research: A systematic review. BMC Med. Ethics 2013, 14, 54. [CrossRef]

17. Owen, G.S.; Martin, W.; Gergel, T. Misevaluating the Future: Affective Disorder and Decision-Making Capacity for Treatment-A Temporal Understanding. Psychopathology 2018, 51, 371-379. [CrossRef]

18. Bilanakis, N.; Peritogiannis, V.K.; Vratsista, A. Treatment decision-making capacity in hospitalized patients with schizophrenia. Psychiatr. Psychiatr. 2017, 28,37-45. [CrossRef]

19. Mandarelli, G.; Carabellese, F.; Parmigiani, G.; Bernardini, F.; Pauselli, L.; Quartesan, R.; Catanesi, R.; Ferracuti, S. Treatment decision-making capacity in non-consensual psychiatric treatment: A multicentre study. Epidemiol. Psychiatr. Sci. 2018, 27, 492-499. [CrossRef]

20. Morán-Sánchez, I.; Luna, A.; Pérez-Cárceles, M.D. Assessment of capacity to consent to research among psychiatric outpatients: Prevalence and associated factors. Psychiatr. Q. 2016, 87, 89-105. [CrossRef]

21. Palmer, B.W.; Dunn, L.B.; Appelbaum, P.S.; Mudaliar, S.; Thal, L.; Henry, R.; Golshan, S.; Jeste, D.V. Assessment of Capacity to Consent to Research Among Older Persons with Schizophrenia, Alzheimer Disease, or Diabetes Mellitus: Comparison of a 3-Item Questionnaire with a Comprehensive Standardized Capacity Instrument. Arch. Gen. Psychiatry 2005, 62, 726-733. [CrossRef]

22. Raymont, V.; Bingley, W.; Buchanan, A.; David, A.S.; Hayward, P.; Wessely, S.; Hotopf, M. Prevalence of mental incapacity in medical inpatients and associated risk factors: Cross-sectional study. Lancet 2004, 364, 1421-1427. [CrossRef]

23. Fernandez, C.; Kennedy, H.G.; Kennedy, M. The recovery of factors associated with decision-making capacity in individuals with psychosis. BJPsych Open 2017, 3, 113-119. [CrossRef]

Publisher's Note: MDPI stays neutral with regard to jurisdictional claims in published maps and institutional affiliations.

(C) 2020 by the authors. Licensee MDPI, Basel, Switzerland. This article is an open access article distributed under the terms and conditions of the Creative Commons Attribution (CC BY) license (http://creativecommons.org/licenses/by/4.0/). 